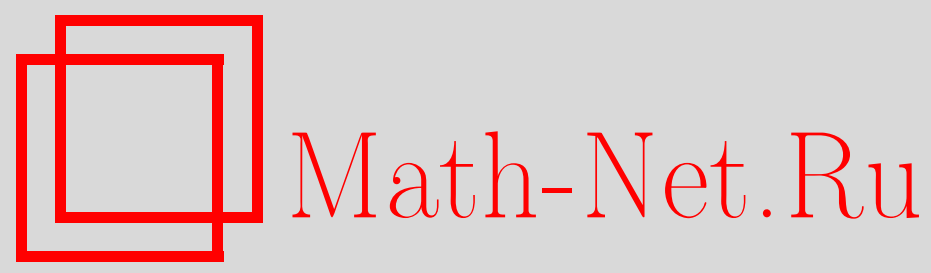

А. Г. Макаренко, Особенности фильтрационного горения пористых материалов, Вестн. Сам. гос. техн. ун-та. Сер. Физ.-мат. науки, 1999, выпуск 7, 121-126

DOI: https://doi.org/10.14498/vsgtu215

Использование Общероссийского математического портала Math-Net.Ru подразумевает, что вы прочитали и согласны с пользовательским соглашением

http://www.mathnet.ru/rus/agreement

Параметры загрузки:

IP : 54.80 .97 .219

26 апреля 2023 г., 11:23:28

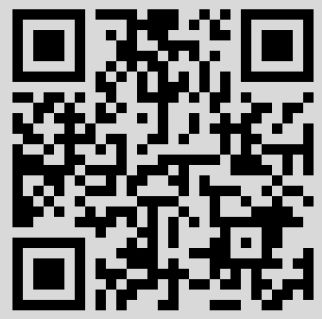




\title{
ОСОБЕННОСТИ ФИЛЬТРАЦИОННОГО ГОРЕНИЯ ПОРИСТЫХ МАТЕРИАЛОВ
}

\begin{abstract}
Рассматривается модель газогенератора, представляющего собой пористую пиротехническую смесь, заключенную в полузамкнутую оболочку, и работающего в режиме спутной фильтрачии. Определяющие соотночения получены на основе уравнений тепломассопереноса, фильтрачии газов и химической кинетики, с помочью которых рассчитаны критические значения длины заряда газогенератора и давления газа. Результаты, полученные в данной работе, легли в основу рекомендачий безопасного производства и применения пиротехнических газогенераторов.
\end{abstract}

Пористые материалы широко используются в процессах горения. Так в средствах пожаротушения пшироко применяются различные газогенерирующие и аэрозолеобразующие составы, используемые как их компоненты, так и самостоятельно. Эти составы представляют собой порошковые смеси с высокой пористостью. Многие пожароопасные материалы также являются пористыми (зерно, уголь, различные материалы в горючей упаковке и др.), которые способны зажигаться и гореть по фильтрационному механизму. Причем замечено, что материалы с высокой пористостью наиболее склонны к самовозгоранию [1]. Этому способствует развитая поверхность и низкая теплопроводность пористого материала. В связи с этим изучение закономерностей фильтрационного горения пористых материалов представляется весьма актуальным.

Среди средств пожаротушения весьма эффективными и надежными показали себя средства, созданные на основе газогенерирующих устройств для наддува и вытеснения дисперсных и жидких сред. Основным преимуществом подобных устройств является быстрота приведения в действие и низкая температура газообразных продуктов горения. Газогенерирующие элементы ЭГ-2 для огнетушителя ОПУ-2 выпускаются серийно уже более 5 лет и отлично зарекомендовали себя. Кроме того сами продукты горения могут успешно тушить очаги загорания. В частности, например, были проведены испытания газогенератора азота, который в течение 5 с выделял $1,5 \mathrm{~m}^{3}$ газа с температурой менее $70^{\circ} \mathrm{C}$. В результате очаг пожара в замкнутом объеме был потушен. Сейчас широкое распространение получают системы объемного тушения (СОТ). Они обладают высокой огнетушащей способностью, но вместе с тем имеют высокую температуру продуктов горения, в которых, кроме того, значительное количество окислов щелочных металлов. В настоящее время имеются опытные образцы газоаэрозольного огнетушителя, продукты горения которого имеют температуру менее $100^{\circ} \mathrm{C}$, а генерируемый аэрозоль содержит в своем составе $\mathrm{N}_{2}, \mathrm{CO}_{2}, \mathrm{KCl}$ и $\mathrm{NaCl}$. Подобные огнетушители могут найти применение при защите дорогостоящей оргтехники (компьютеров), складов продуктов, медпрепаратов и т.п., где даже в экстремальных ситуациях допустим контакт только с инертными материалами.

В большинстве случаев основу газогенераторов и газогенерирующих элементов составляет пористая пиротехническая смесь, горение которой происходит с фильтрацией газов.

Фильтрационным называют такое горение, при котором имеет место фильтрация газа через зону горения. Вследствие этого одним из основных факторов теплопереноса, наряду с кондуктивным, становится конвективный теплоперенос. Его значимость возрастает с увеличением пористости, так как рост пористости материала снижает его теплопроводность.

Различают несколько режимов фильтрационного горения: спутный и встречный, с принудительной и естественной фильтрацией, с фильтрацией химически активного и химически инертного по отношению к материалу газа. Режимы спутной и встречной фильтрации различаются направлением фильтрации газа по отношению к направлению движения фронта горения. Если они направлены в одну сторону - спутный, в противоположные - встречный. Одним из примеров фильтрационного горения с химически активным газом является горение пористого горючего при фильтрации окислителя. Если расход газа задан искусственно, то имеет место принудительная фильтрация. В естественном режиме фильтрация реализуется за счет градиентов давлений, возникающих при горении пористого материала. 
Механизмы некоторых из этих режимов хорошо изучены в работах [2-5]. Так было установлено, что при спутной фильтрации, возможен такой режим горения, при котором достигается температура выше адиабатической. Это необычное явление объясняется тем, что происходит конвективный перенос тепла из зоны горячих продуктов горения в зону горения. Этот факт имеет большое значение для взрывопожаробезопасности, так как позволяет применять вещества, не способные к самопроизвольному зажиганию и горению в компактном беспористом состоянии.

Изучение волнового механизма фильтрационного зажигания пористого материала показало, что фильтрация нагретого газа значительно облегчает зажигание и в десятки раз сокращает время задержки зажигания по сравнению с кондуктивным нагревом беспористого материала [6]. Изучение теории фильтрационных процессов применительно к зажиганию пористых материалов позволило разработать математическую модель и экспериментально исследовать фильтрационное зажигание некоторых материалов [7]. При этом было установлено, что многие материалы, считающиеся сравнительно безопасными в компактном беспористом состоянии, могут быть весьма опасными в пористом.

Для изучения фильтрационного горения пористого материала была использована модель газогенерирующего элемента, представляющая собой пористую пиротехническую смесь, помещенную в полузамкнутую оболочку (рис.1). Смесь способна гореть без доступа воздуха и с

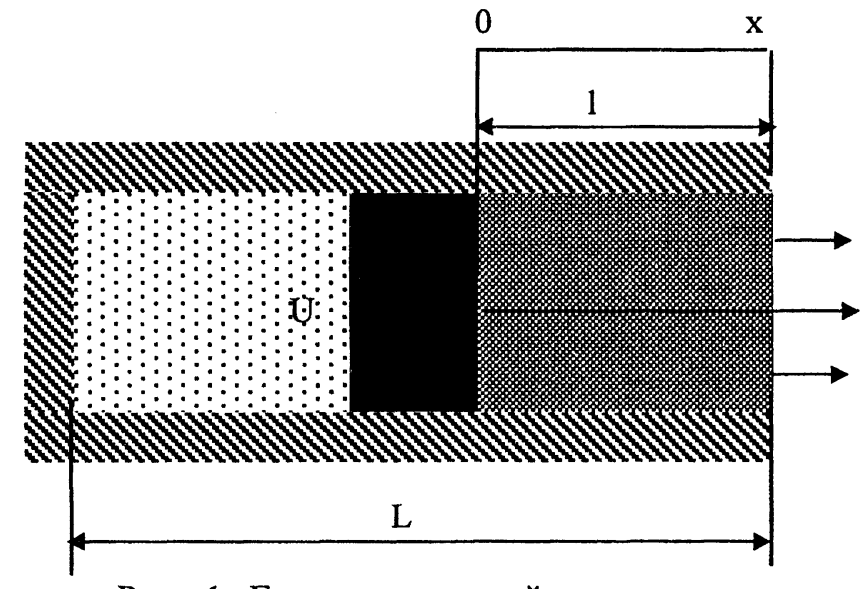

Р и с. 1. Газогенерирующий элемент выделением газообразньг продуктов горения. Если ее зажечь с "глухого" торца, то фронт и газообразные продукты горения будут распространяться в одном направлении - к "открытому" торцу. Реализуется режим спутной фильтрации.

Для оценки максимального давления, которое развивается в камере газогенератора при горении состава, можно решить несложную задачу, описывающую процесс газовыделения в полузамкнутой камере , т.е. когда она имеет отверстие в крышке или стенке. Здесь устанавливается стационарный режим, когда скорость газовыделения в реакто-

ре $m+$ и газоотвода из него $m$ - сравниваются:

$$
m_{+}=u_{0} \rho_{k} S_{+} a_{\Gamma}, \quad m_{-}=v_{\Gamma} \rho_{\Gamma} S_{-},
$$

где $u_{0}$ - линейная скорость горения; $\mathrm{v}_{\Gamma}$ - скорость истечения газа из камеры; $\rho_{k}$-плотность состава; $\rho_{\Gamma}$ - плотность газа; $S_{+}$- площадь сечения реактора; $S_{-}$- площадь сечения газоотводного канала; $a_{\Gamma}$-доля газообразных продуктов.

Связь $a_{\Gamma}$ и $\hat{V}$ имеет вид $a_{\Gamma}=\hat{V} \rho_{\Gamma}$, где $[\hat{V}]=\mathrm{cm}^{3} / \Gamma ; \rho_{\Gamma}$-плотность при $\mathrm{T}_{0}=300 \mathrm{~K}$, $\mathrm{p}=1$ атм.; $u_{\Gamma}$ определяется перепадами давлений в газоотводном канале:

$$
v_{\Gamma}=\left.\eta \frac{d p}{d x}\right|_{S_{-}}=\eta \frac{p_{+}-p_{-}}{L},
$$

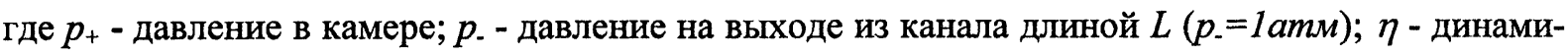
ческая вязкость газа.

Полагаем $p_{+}>>p$. и $p_{+}-p . \approx p_{+}$. Тогда, приравнивая выражения для скоростей газовыделения и газоотвода, имеем

$$
u_{0} \rho_{k} S_{+} \hat{V} \rho_{\Gamma}=\eta \frac{p_{+}}{L} \rho_{\Gamma} S_{-}
$$

и, далее, получаем выражение для давления 


$$
p_{+}=\frac{u_{0} \rho_{k} \hat{V L} S_{+}}{\eta S_{-}},
$$

которое не учитывает параметры фильтрации газа, а также влияние температуры газа на максимальное давление в камере. Поэтому необходимо решать более сложную тепловую задачу, учитывающую процесс фильтрации газа.

В соответствии с теорией фильтрационного горения [2] поток фильтрующегося газа приводит к изменению температуры в зоне реакции, а следовательно, и скорости горения. Для описания этого процесса должна быть рассмотрена система уравнений тепло-массопереноса в пористой среде с нелинейными источниками, отражающая изотермическое превращение реагентов:

$$
\begin{gathered}
c_{v} \frac{\partial T}{\partial t}=\frac{\partial}{\partial x} \lambda \frac{\partial T}{\partial x}-c_{g} \rho_{g} v_{f} \frac{\partial T}{\partial x}+Q \rho_{0} W, \\
\frac{\partial \rho_{g}}{\partial t}=-\frac{\partial}{\partial x}\left(\rho_{g}, v_{f}\right)+\mu \rho_{o} W, \\
\frac{\partial \eta}{\partial t}=W ; W=k_{o} \exp \left(-\frac{E}{R T}\right) f(\eta) p^{v}, \\
v_{f}=-k_{f} \frac{\partial p}{\partial x} ; p_{g}=\rho_{g} R_{1} T ; \rho_{p}=\rho_{o}\left(1-v_{1}\right) \eta ; \\
\eta=\left(\rho_{0}-\rho\right) / \rho_{0} ; c_{v}=c_{g} \rho_{g}+c \rho+c_{p} \rho_{p} .
\end{gathered}
$$

Начало координат $(x=0)$ связано с фронтом горения; $L$ - длина газогенератора; $l$ - длина несгоревшей части исходной смеси.

В системе: $T$ - температура; $P$ - давление газа; $\eta$-степень(полнота) превращения вещества; $v_{l}$ - удельное газовыделение единицы объема исходной шихты ; $\rho_{g}$ и $\rho_{0}$ - плотности газа и исходной шихты соответственно; $C_{V}$ - средняя теплоемкость при $V=c o n s t ; C_{P}$ - теплоемкость газообразных и конденсированных продуктов в газогенераторе при постоянном давлении; $Q$ - теплота, выделяющаяся при сгорании 1 г исходной шихты, не зависящая от температуры; $\lambda$ коэффициент теплопроводности; $k_{0}$ - предэкспоненциальный множитель; Е - энергия активации; $R$ - универсальная газовая постоянная; $\mu$ - молекулярная масса газообразных продуктов; $W$ - скорость химической реакции; $k_{f}$ - коэффициент фильтрации.

Анализ такой системы уравнений возможен только при использовании численных методов. Однако модель можно значительно упростить, приняв во внимание особенности распространения фронта горения в условиях спутной фильтрации.

Прежде всего упростим уравнение (1). Заметим, что размеры зоны прогрева $l_{n p}=u / a$, где $a=\frac{\lambda}{c \rho}$, а $u$ - линейная скорость горения. Так как зона прогрева намного меньше длины пористого элемента, то теплообменом на торцах можно пренебречь. Следовательно, его можно рассматривать как бесконечный. Преобразовав уравнение (1), связав систему координат с фронтом горения, получим

$$
u c_{v} \frac{d T}{d x}=\frac{d}{d x} \lambda \frac{d T}{d x}-c_{g} \rho_{g} v_{f} \frac{d T}{d x}+Q \rho_{o} \frac{d \eta}{d x} u
$$

Интегрируя уравнение (5), находим

$$
T_{2}-T_{0}=\frac{Q \rho_{o}}{c \rho_{o} u-\rho_{g} \nu_{g}} u
$$

При этом учитывается, что давление газа в точке $\mathrm{x}>0$ постоянно. Это объясняется тем, что массовый газовый поток через исходные реагенты также не зависит от координаты $\mathrm{x}$, если $\mathrm{x}>0$.

Для вывода выражения зависимости скорости горения от основных параметров процесса был использован метод узкой зоны Зельдовича и Франк-Каменецкого. В соответствии с ним в волне горения выделены две зоны. Первая - зона реакции, где скорость химических превращений весьма высока. Вторая - зона прогрева, где тепловыделением от химической реакции можно 
пренебречь, и нагрев происходит за счет тепла из первой зоны. В этом случае скорость горения имеет вид

$$
u^{2}=k_{\eta} a k_{0} \exp \left(-\frac{E}{R T_{c o m}}\right)\left(\frac{c R T_{c o m}^{2}}{E Q}\right)
$$

где $a$ - коэффициент, зависящий от вида функции $f(\eta)=\int_{0}^{1} \frac{T_{c o m}-T_{i n}-q_{\eta}}{f(\eta)} d \eta$ и приблизительно равньй 1.

Для определения газового потока, фильтрующегося через пористое вещество, оценим давление в сгоревшей смеси без истечении газа из него (замкнутая оболочка). Из экспериментов известно, что при горении выделяется 50 - 70 мл газа на 1 г исходной смеси при нормальных условиях. Использовав уравнения состояния газа, получили $P=30-40 \mathrm{MПа}$, что намного больше экспериментально полученных $\left(P_{\text {мах }}=2\right.$ MПа). Из этого заключили, что наибольшее количество газа удалено из смеси. Этот факт позволил пренебречь переменным членом в уравнении фильтрации. Здесь принимается, что процесс фильтрации является квазистационарным процессом и скорость фильтрации больше скорости горения:

$$
\frac{d}{d x} \rho_{g} v_{f}=-\mu \rho_{0} W
$$

Изменение давления от $P_{\text {гор }}$ до $P_{\text {атм }}$ происходит на участке несгоревшей смеси, где скорость реакции можно принять равной нулю. Тогда уравнение (7) имеет следующий вид:

$$
\frac{d \rho_{g} v_{f}}{d x}=0
$$

Объединив уравнение фильтрации с уравнением (8), получаем

$$
\rho_{g} v_{f}=\frac{k_{f}}{R_{1} T_{i n}} \frac{p_{*}^{2}-p_{o}^{2}}{2 l} .
$$

Распределение давления в несгоревшей части смеси описывается уравнением

$$
\frac{P_{g}^{2}(x)-P_{o}^{2}}{P_{*}^{2}-P_{0}^{2}}=\frac{x}{l} \text {. }
$$

Для завершения системы уравнений используется уравнение массового баланса газообразных продуктов горения

$$
\frac{d M}{d t}=q_{+}-q_{-},
$$

где $M$ - масса газа, приходящегося на единицу площади поперечного сечения смеси;

$q_{+}$- газовыделение, приходящееся на единицу площади поперечного сечения смеси,

$$
q_{+}=u v_{1} \rho_{o}
$$

q. - отток газа, приходящийся на единицу площади поперечного сечения смеси,

$$
q_{-}=\rho_{g} v_{f}=\frac{k_{f}}{R_{1} T_{i n}} \frac{P_{*}^{2}-P_{o}^{2}}{2 l} .
$$

Длина сгоревшей части смеси составляет $L-l$, а несгоревшей $l$. Количества газа в этих частях соответственно составляют

$$
\begin{gathered}
M_{1}=\rho_{g} T_{c o m}(L-l)=\frac{P_{t}}{R_{I} T_{g}} m, \\
M_{2}=\int_{o}^{l} \rho_{g}\left(x, T_{i n}\right) d x ; M_{2}=\int_{o}^{l} \frac{m}{R_{1} T_{i n}} \sqrt{\frac{x}{l} P_{*}^{2}+P_{o}^{2}},
\end{gathered}
$$

где $\mathrm{m}$ - пористость.

Из эксперимента известно, что давление во фронте горения больше 1 МПа. Тогда, пренебрегая $\mathrm{P}_{0}$, получаем

$$
M_{2}=\frac{2 m l P_{*}}{3 R T_{i n}}
$$


Очевидно, что

$$
\frac{d M_{1}}{d t}+\frac{d M_{2}}{d t}=\frac{d P_{*}}{d t}\left(\frac{2 m l}{3 R T_{i n}}+\frac{m l}{R_{1} T_{c o m}}\right)+P_{*} u\left(\frac{2 m}{3 R_{1} T_{i n}}+\frac{m}{R_{1} T_{c o m}}\right) .
$$

Из условия стационарности следует

$$
\frac{d P_{*}}{d t}\left(\frac{2 m l}{3 R_{1} T_{\text {in }}}+\frac{m l}{R_{1} T_{\text {com }}}\right)+P_{*} u\left(\frac{2 m}{3 R_{1} T_{\text {in }}}+\frac{m}{R_{1} T_{\text {com }}}\right)=u v_{1} \rho_{0}-\frac{k_{f}}{R_{1} T_{\text {in }}}\left(\frac{P_{*}^{2}-P_{o}^{2}}{2 l}\right) .
$$

В результате получаем систему уравнений:

$$
\begin{aligned}
& T_{\text {com }}-T_{\text {in }}=\frac{Q \rho_{0} u}{c \rho_{0} u-\rho_{g} v_{f}} \\
& \rho_{g} v_{f}=\frac{k_{f}\left(P_{*}^{2}-P_{o}^{2}\right)}{R} \frac{1}{T_{i n} 2 l} \\
& u^{2}=k_{\eta} a k_{o} \exp \left(-\frac{E}{R T_{c o m}}\right)\left(\frac{c R T_{c o m}}{E q}\right) \text {; } \\
& d l / d t=u \\
& \frac{d P_{*}}{d t}\left(\frac{2 m l}{3 R T_{\text {in }}}+\frac{m l}{R_{1} T_{\text {com }}}\right)+\left(\frac{2 m}{3 R T_{\text {in }}}+\frac{m}{R_{1} T_{\text {com }}}\right) P_{*} u=u v_{1} \rho_{0}-\frac{k_{f}}{R_{1} T_{i n}}\left(\frac{P_{*}^{2}-P_{0}^{2}}{2 l}\right) .
\end{aligned}
$$

Начальные условия: $T=T_{0}, l=L, P=P_{0}$.

Проанализируем систему уравнений (18) - (22). Из физики процесса понятно, что для формирования квазистационарного профиля давления некоторая часть исходной смеси должна уже сгореть.

Примем, что моменту $t$ * соответствуют значения давления $P_{*}$ и длины $l_{*}$. Для $t<t *$ длина зоны фильтрации меньше, чем длина несгоревшей части. С увеличением $t$ длина зоны фильтрации растет, а несгоревшей части уменышается.

По условию стационарности вся масса газов, образовавшихся при горении, фильтруется в несгоревшую смесь. Тогда можно оценить максимальное давление:

$$
P_{*_{\max }}^{2}-P_{0}^{2}=\frac{u \rho_{0} v_{1} R_{1} T_{\text {in }}}{k_{f}} .
$$

Использовав (18) и (22) и подставив в них максимальные значения, получаем

$$
\frac{2 m}{3 R T_{\text {in }}}\left(l_{*}, P_{* \text {, } \max }\right)=\left(L-l_{*}\right) \rho_{0} v .
$$

Значение $l$ * соответствует длине несгоревшего участка в момент развития максимума давления и имеет значение

$$
l_{*}=\frac{L \rho_{0} v_{1}}{\rho_{0} v_{1}+P_{*_{\mathrm{m} \mathrm{ax}}} \frac{2 m}{3 R_{1} T_{i n}}} .
$$

По условию квазистационарности процесса можно рассчитать время, зная скорость горения

$$
t_{*}=\frac{l_{*}}{u} \text {. }
$$

При условии $0<t<t$ * давление растет из-за роста скорости горения (нестационарный режим). Длина зоны фильтрации при $t>t$ * равна длине несгоревшего участка. На этом участке давление уменьшается, так как уменьшается длина зоны фильтрации.

Теоретические результаты были подтверждены экспериментально и использованы при разработке способа и пиротехнического устройства получения газов [8].

Экспериментальные исследования показали, что в данных условиях могут самостоятельно гореть низкокалорийные системы с коэффициентом избытка окислителя $\alpha=0,1-0,3$, в том числе вещества, не способные к самостоятельному горению на открытом воздухе. 
Так при исследовании состава, специально разработанного для снаряжения газогенерирующих элементов, было установлено, что в обычньх условиях он не способен к самостоятельному горению. Но если данный состав поместить в полузамкнутую оболочку, он сгорает спокойно. Однако в таких условиях скорость горения и уровень внутрикамерного давления

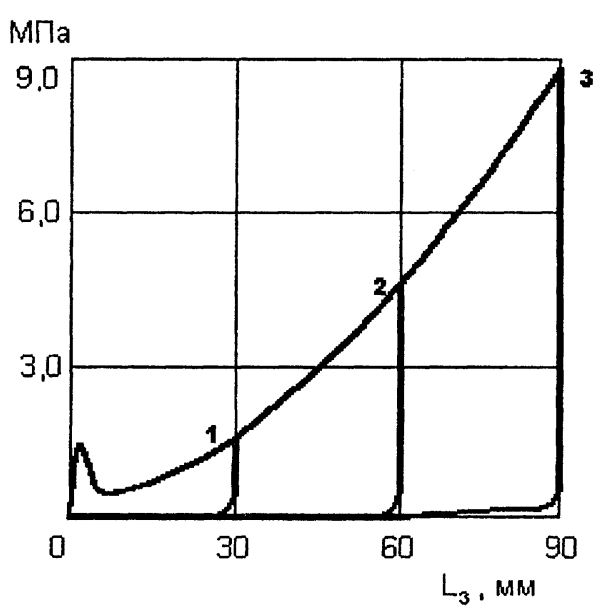

Р и с. 2. Профили давлений внутри камеры. Время перемещения фронта горения: $1-2,0 ; 2-2,7 ; 3-3,2 \mathrm{c}$

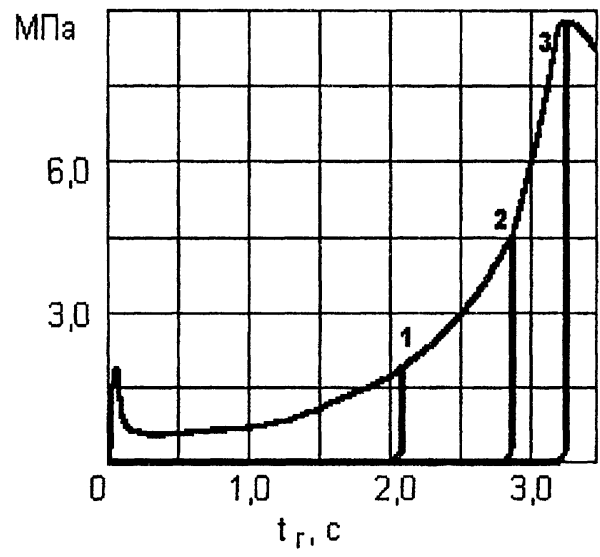

Р и с. 3. Динамика газообразования. Длина заряда: 1 - 30; 2 - 60; 3 - 90 мм возрастают по длине пористого тела, о чем свидетельствуют профили давления, которые имеют вид ступенек с довольно крутым передним фронтом (рис.2), и график динамики газообразования (рис.3).

Сравнение этих результатов с замерами температур по длине заряда показало, что резкое повышение давления в каждой точке соответствует моменту прохождения этой точки фронтом горения. До этого, несмотря на опережающее движение части газов перед фронтом горения, давление в несгоревшей части заряда практически равно атмосферному. Позади фронта горения давление внутри камеры равномерно распределено по длине, однако его уровень и давление во фронте растут с увеличением сгоревшей части заряда.

Таким образом, можно сделать выводы.

1.Разработана модель расчета основных параметров процесса фильтрационного горения.

2.Получено выражение для расчета давления и скорости горения в зависимости от длины несгоревшей части смеси.

3.Получены выражения для максимального давления и времени достижения этого давления в процессе фильтрационного горения.

4.Проведена сравнительная оценка полученных расчетным путем данных с данными эксперимента.

5.Рассмотрена область практического применения реализуемого режима горения. Доказана возможность создания на его основе газо- и аэрозолеобразующих составов, которые используются как самостоятельные (аэрозольные и газовые огнетушители), так и вспомогательные (для надцува порошковых огнетушителей и вытеснения дисперсныт и жидких сред) средства пожаротушения

\section{БИБЛИОГРАФИЧЕСКИЙ СПИСОК}

1. Корольченко А.Я. Пожаровзрывоопасность промышленной пыли. М.: Химия, 1986.

2. Алдуиин А.П., Мержанов А.Г. Теория фильтрационного горения- общие представления состояние исследований // Распространение тепловых волн в гетерогенных средах. Новосибирск: Наука. Сиб.отд. АН СССР, 1988.

3. Алдугин А.П., Ивлева Т.П., Мержанов А.Г и др. Распространение фронта горения в пористых металлических образцах при фильтрации окислителя // Процессы горения в химической технологии металлургии. Черноголовка: ОИХФ АН СССР, 1975. С. 245-252.

4. Алдуиин А.П. О механизме горения СВС-систем с газифицирующимся окислителем .// Проблемы технологического горения. Т.1.Кинетика, термодинамика, механизм и теория горения. Черноголовка: ОИХФ АН СССР. 1981. C.11-21.

5. Алдушин А.П., Сеплярский Б.С. Распространение волны экзотермической реакции в пористой среде при продуве газа //ДАН СССР. 1978. 241. №1. С. 72-75.

6. Сеплярский Б.С. Воспламенение конденсированньх систем при фильтрации газа // Физика горения и взрыва. 1991. №1,.C.3-12. 